\title{
Choice Behaviour of Housing Attributes: Theory and measurement
}

\author{
Bako Zachariah Zinas ${ }^{1}$ Mahmud Mohd Jusan² \\ ${ }^{1}$ PhD Student, ${ }^{2}$ Senior Lecturer, \\ Department of Architecture, Universiti Teknologi Malaysia (UTM) \\ zinasbako@yahoo.co.uk
}

\begin{abstract}
Preferences and choices in a society are constant dynamic operations, made based on the behavioural dynamism of people. In this cosmic dynamism, they keep shifting from one stage to another, within the same cosmic space. Housing preferences and choices, like any other life interests, therefore operate within this framework. Unlike merchandized products brands, housing brands are hardly known, probably because of the heterogeneous nature of the housing product - the house. However, very little is known about the relevant housing attributes (refer to page 7). Housing preferences and choices operate within the framework of preferences and choices for housing attributes. In any preference and choice activity, there are underlying motivations that make it possible for an individual to choose from available alternatives within a given product field. This paper examines and outlines the methodological and theoretical framework of housing preferences and choices, based on the theory of means-end chain (MEC). Previous MEC applications in the field of architecture and urban design have been very useful and successful. The paper attempts to explore from literature the possibility of extending the previous methods and their applicability in design process. In dealing with user preference for housing, there is a need for research for a development of a technological tool to identify user needs and preference, and the kind of decision support that is required to identify these needs.
\end{abstract}

Keywords: housing preference and choice, means-end chain, laddering technique, models

eISSN 2514-751X @ 2017 The Authors. Published for AMER ABRA by e-International Publishing House, Ltd., UK.. This is an open access article under the CC BY-NC-ND license (http://creativecommons.org/licenses/by-ncnd/4.0/). Peer-review under responsibility of AMER (Association of Malaysian Environment-Behaviour Researchers), ABRA (Association of Behavioural Researchers on Asians) and cE-Bs (Centre for EnvironmentBehaviour Studies), Faculty of Architecture, Planning \& Surveying, Universiti Teknologi MARA, Malaysia.

https://doi.org/10.21834/aje-bs.v2i2.175 


\subsection{Introduction}

Preferences and choices are lifetime phenomena. Every person lives and operates within the framework of choosing from alternatives of life's endeavours in whatever area. Preference is a function of choice. Molin et al. (1996) put it this way, "choices are assumed to reflect preferences". We live in a world of shifting preferences and choices; and in a society that is in a constant dynamic operation, preferences and choices are made based on the behavioural dynamism of people. In this cosmic dynamism, preferences and choices keep shifting from one stage to another within the same cosmic space. The choice process is considered to be a dynamic process in which people identify a problem to be solved (Coolen \& Hoekstra, 2001). Molin et al. (1996) assert that it is only in the act of actual choice that individuals can reveal their preferences. Housing preferences and choices like any other life interests therefore operate within this framework. Timmermans et al. (1994) and Coolen \& Hoekstra (2001) state that the topic of housing choice and housing preference continues to be heavily researched, as an area of interest to scholars in various and numerous disciplines. Although housing brands are hardly known, much is known about the relevant housing attributes (Coolen \& Hoekstra, 2001). Housing preferences and choices operate within the framework of preferences and choices for housing attributes. In any preference and choice activity, there are underlying motivations that make it possible for an individual to choose from available alternatives within a given product field. What motivate housing users to choose and/or prefer a given set of attributes over and above other sets of attributes? Preferences and choices are regarded as value-oriented and goaldirected activities (Coolen \& Hoekstra, 2001). What instruments measure these choice behaviours?

The Means-End Chain (MEC) model (Gutman, 1982) originally developed for merchandized products, of which application in the field of architecture and urban design has been very useful and successful in the past few decades (Tania et al., 2006), is the framework within which this paper is anchored. MEC utilizes the laddering technique for data collection, analysis and interpretation (Mahmud, 2007; Coolen \& Hoekstra, 2001). Many different approaches in measuring user preferences have been suggested or developed, ranging from simple direct questioning of respondents to sophisticated measurement approaches such as conjoint analysis, which allows researchers to test the assumptions underlying their measurement approaches. Conjoint analysis is a measurement approach in which users are requested to express their preference for attribute profiles, which are constructed according to an experimental design (Orzechowski, 2004).

There are basically two broad modelling approaches to measure housing choice and preference- the revealed housing choice models and the stated housing preference and choice models. Revealed models are based on observational data of households' actual housing choices in real markets; while stated models are based on the premise that observed choices will also reflect the joint influence of preferences, market conditions and 
availability (Timmermans et al., 1994). These models are based on people's expressed preferences and choices. Stated models are classified into algebraic and non-algebraic methods. The algebraic models are compositional and decompositional or conjoint models, while non-algebraic models are decision plan nets and measurement or residential image approach.

\subsection{Objective of the Study}

This paper is a conceptual one, geared towards presenting a research platform using the Means-End Chain (MEC) model for housing researchers, and also initiating an interest for housing researchers in employing the use of MEC model as a research tool. The sole objective is to "market" the MEC research model as a tool for measuring housing attributes in choice behaviour research.

\subsection{Significance of the Study}

Housing is a complex and heterogeneous product in its setting, the cognitive structures of housing users for housing attributes is also complex as well as their choice behaviours. The Means-End Chain (MEC) model has been found in its application to successfully handle and measure these complexities in housing research. The adoption and application of MEC model in measuring these complexities in housing is the significance of this paper.

\subsection{Limitation of the Study}

This paper is limited to presenting only a conceptual framework for conducting housing research using the MEC model and other models for choice and preference of housing attributes, and the corresponding choice behaviours. It is not presented as a research paper.

\subsection{Theoretical Framework of MEC Theory}

This section provides a brief overview of theoretical framework of MEC theory used in research process. It explains what MEC is, its underlying concept, its variables, and the methodology in MEC for data collection, analysis and interpretation.

\subsection{The Means-End Chain (MEC)}

MEC has a long research history. Gutman (1982) first introduced the concept, with a focus on qualitative in-depth understanding of consumer motives. Reynolds and Gutman (1988) made MEC well-accepted by providing a hands-on description of how to conduct, analyse and use MEC interviews (Weijters \& Muylle, 2008). Kaciak and Cullen (2006) assert that MEC has been a popular and ever-evolving research domain since its introduction. Gutman's MEC theory (1982) was inspired by research from Rokeach (1968), and Yankelovich (1981) who showed that values direct people's behaviour in all aspects of their 
lives (Boer \& McCarthy, 2004). Although MEC original purpose was for linking consumers' values to their choice behaviour in marketing and consumer research, it is becoming popular in other areas (Tania et al., 2006) like architecture, urban design, advertising, information technology, and organisational management (Rugg et al., 2002).

Gutman (1982) defines MEC as a model that seeks to explain how a product or service selection facilitates the achievement of desired end states. MEC links sequentially products' attributes $(A)$ to consequences of product use $(C)$ and to individuals' personal values $(V)$. The resultant $\mathrm{A}-\mathrm{C}-\mathrm{V}$ sequence forms what is called means-end chain or ladder. Coolen et al. (2002) view MEC as a model that relates the choice of a good (defined as a collection of attributes) to its contribution to achieving objectives and values. They explain that "means" are objects (products) or activities in which people engage e.g. running, reading, cooking, etc, and "end" refers to valued states of being, such as, happiness, security, and accomplishment.

The essential idea in MEC theory is that consumers choose actions which produce the desired consequences and which minimise the undesirable consequences. Reynolds and Whitlark (1995) paradoxically stress that while a means can be an end, an end can also be a means. Meesters (2005) opines that in order to make the right choice between the different goods with different consequences, the consumer must learn which good possesses the attributes producing the desirable consequence.

\subsection{Assumptions of MEC}

The original MEC model by Gutman (1982) is based on four assumptions. First, it assumes that objectives and values influence choice processes; secondly, it assumes that people can keep track of the enormous diversity of goods by grouping them in sets or classes so as to produce the complexities of choice; thirdly, it assumes that behaviour of consumers has consequences, although these consequences do not have to be for everybody; and fourthly, it assumes that consumers learn to associate particular consequences with particular behaviours (Gutman, 1982; Coolen \& Hoekstra, 2001; Tania et al., 2006).

\subsection{Conceptual structure of MEC}

The variables or constructs of the original structure of MEC model (Gutman, 1982) comprise attributes, consequences and values (Fig. 1). The linkage between values and consequences is of essential importance in the MEC model. Coolen et al. (2002) give the linkages as, firstly, that a certain good must be consumed or used to realise a desirable consequence; and secondly, it is the linkage between consequences and the attributes of goods.

The conceptual model of MEC theory can be summarised in the following propositions (Pieters et al., 1991): firstly, that the subjective knowledge about consumers' goods and services is organised in associative networks; secondly, that the concepts in these networks that are relevant for consumer decision-making are attributes of products, consequences of product use, and consumers' values; thirdly, that attributes, 
consequences and values are ordered hierarchically; and fourthly, that the structure of consumers' knowledge about goods and services influences relevant consumer behaviour (Pieters et al., 1991; Coolen \& Hoekstra, 2001).

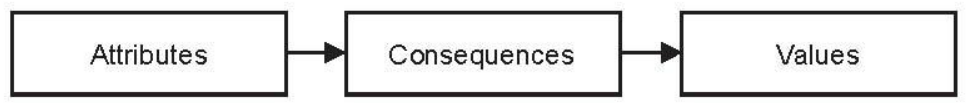

Figure 1: Structure of MEC (Source: Gutman, 1982)

Olson and Reynolds (1983) proposed some modifications on Gutman (1982) model, broadening the chain levels. The broadened model recommends that the attributes be subdivided into concrete and abstract; consequences into functional and psychological; and personal values into instrumental and terminal (Botschen et al., 1999; Valette-Florence \& Rapacchi, 1991). The broadened conceptual framework of MEC model is as illustrated in Figure 2.

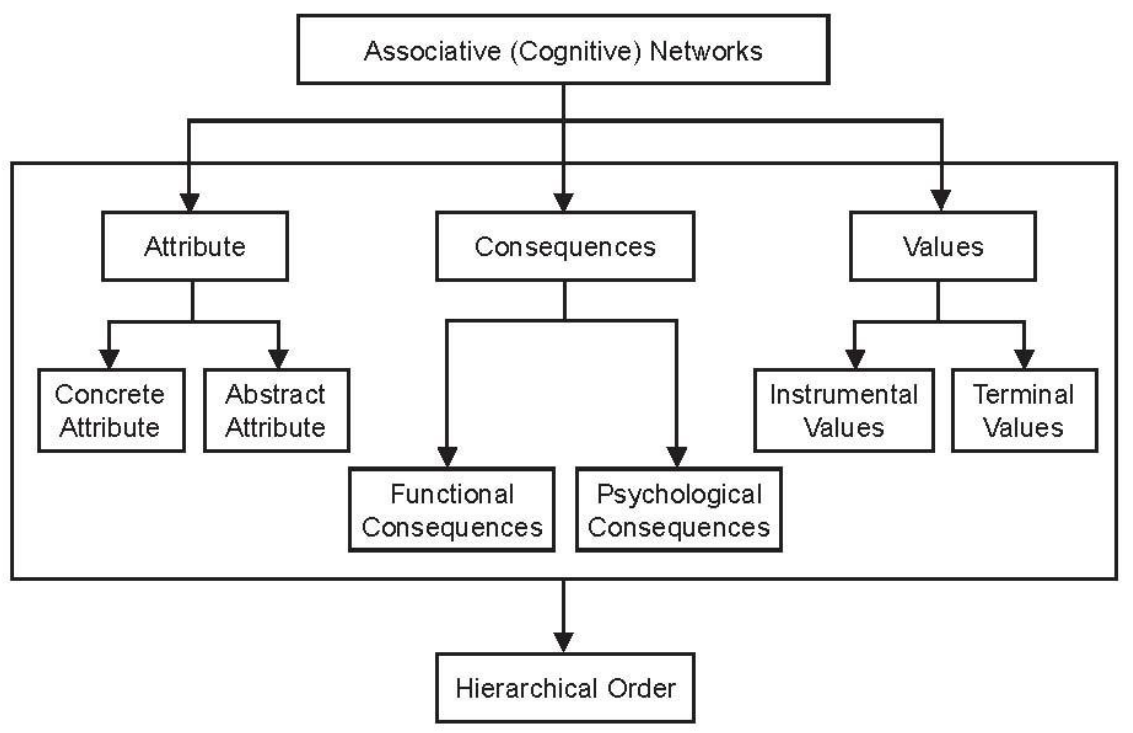

Figure 2: Broadened Structure of MEC Model (Source: Olson \& Reynolds, 1983; Gutman, 1982)

\subsubsection{Attributes}

The New Webster's dictionary defines attribute as "a quality proper to a characteristic of a person or thing". Valette-Florence and Rapacchi (1991) view attributes as features or 
aspects of products or services. Gengler et al. (1999) perceive them as relatively concrete meanings that represent physical or perceptible characteristics in a product. According to Botschen et al. (1999), attributes are characteristics of products, services, or behaviour that are preferred or sought for by consumers. While agreeing to all these definitive views, attributes can be seen as the intrinsic and physical features, properties or characteristics that define a product or person.

Attributes are of two levels: concrete attributes and abstract attributes (Olson \& Reynolds, 1983). Abstract attributes are defined as the directly perceptible physical characteristics of a product, e.g. price, color, and weight (Vriens \& Hofstede, 2000), relatively intangible characteristics, such as style and brand (Lin, 2002), or perceived value or importance (Botschen et al., 1999). Mahmud (2007) classifies concrete attributes into two groups, namely, element and relationship, as it relates to housing. He sees abstract attributes as "meanings" perceived by the housing consumer.

\subsubsection{Consequences}

'Consequences' can be defined as "that which follows something and arises from it" (New Webster's Dictionary, 1995). Coolen and Hoekstra (2001) consider consequences as every direct or indirect result of a person's behaviour. They are the effects produced by a given product; the characteristics that are less directly perceptible in a product or brand, and are the result of various attributes combinations (Vriens \& Hofstede, 2000). Lin (2002) opines that consequences are what the consumer feels after consuming the product, and this might be a positive feeling e.g. benefits, or a negative feeling, e.g. perceived risks. In specific situations, Valette-Florence and Rapacchi (1991) opine that consequences represent behaviours.

Consequences are at the intermediary level in the chain, and have a more abstract meaning that reflects perceived benefits (Gengler et al., 1999). Mahmud (2007) relying on Gutman (1982), states that there are two categories of consequences in Gutman's MEC, namely, functional consequences and abstract consequences. He opines that functional consequences refer to practical benefits and performance outputs, while abstract consequences are feelings or social considerations. Consequences may be physiological (satisfying hunger, thirst, or other physiological needs) or psychological (self-esteem, improve outlook in the future) or sociological (enhance status, group membership) in nature. They may occur directly (e.g. buying a new dress, I feel better) or indirectly (e.g., because I feel better, people react more favourably to me) (Gutman, 1982).

\subsubsection{Values}

Values are at the most abstract level in the chain. Rokeach (1968) defines values as enduring benefits that a particular mode of conduct or particular end-state of existence is personally and socially preferable to alternative modes of conduct or end-states of existence. They are the benefits and relatively stable conditions that have a strong emotional impact e.g. security, happiness, fun, and enjoyment (Vriens \& Hofstede, 2000). 
Dibley and Baker (2001) opine that values determine, regulate, and modify relationships between individuals, organizations, institutions, and societies. According to ValetteFlorence and Rapacchi (1991), personal values provide general guidance and are part of our lives. Schwartz (1994) sees values as "desirable translational goals, varying in importance that serves as guiding principles in the life of a person or other social entities". Values are life's drivers that cause an individual to function in all his actions. They are propellers for preferences and choices in life. They are the reasons for the affection a person has for whatever he has affection for. They coordinate most of a person's behavioural traits in life.

Schwartz (1994) assesses that values can influence behaviour in the following ways: firstly, values contribute to our ability to take a standpoint with respect to political and social questions; secondly, values may be used in the assessment of ourselves and others; thirdly, values play a central part in comparison processes; and fourthly, values may form the criteria for all the evaluation of the opinions, attitudes and actions of ourselves and others (Coolen \& Hoekstra, 2001). In order to be able to live and function in a social environment, both individuals and groups transform the needs that are inherent to human existence into specific values (Coolen et al., 2002; Coolen \& Hoekstra, 2001). Schwartz (1992) states that the central role of values in the human cognitive system stems from three types of human need: the needs of the individual as a biological system; the demands set by coordinated social interaction; and the demands which stem from the functioning and survival groups. From these fundamental human needs, Schwartz $(1992,1994)$ empirically derives ten universal, motivational value domains. These domains are: 1. Power (social power, wealth); 2. Achievement (success, ambition); 3. Hedonism (pleasure, enjoying life); 4. Stimulation (daring, exciting life); 5. Self-direction (independence, curiosity); 6. Universalism (social justice, unity with nature); 7. Benevolence (helping, true friendship); 8. Tradition (modesty, devoutness); 9. Conformity (politeness, self-discipline); 10. Security (family security, cleanness) (Mahmud, 2007; Coolen et al., 2002; Coolen \& Hoekstra, 2001). Each individual strives for values belonging to each of these domains.

According to Rokeach (1973), the values will not be of the same importance for every individual. He clarifies that individuals organise and structure their values so that they are in a position to choose from alternative objectives and actions, and are able to resolve potential conflicts. He calls this configuration of values as a value system, which Coolen et al. (2002) define as "a learned and organised entity of principles and rules that helps people in their choice between alternatives, to resolve conflicts and make decisions". Coolen et al. (2002) further allude that people's choice behaviour is determined by a combination of both the values activated by the choice situation. Rokeach (1973) subdivided values into instrumental and terminal values. Terminal values represent the final states of existence i.e. they are the goals we seek in life, such as peace, self-achievement, and prosperity, and instrumental values are ways of behaving that lead to terminal values, such as ambition and resourcefulness that might be necessary for achieving prosperity (Mahmud, 2007; Tania et al., 2006). 
In a choice situation, various values will be activated in a person's value system. It is unlikely that people will be able to act in agreement with all of the activated values simultaneously (Rokeach, 1973). Blaauboer and Mulder (2007) contrast the choice behaviours of two individuals with similar backgrounds by adjudging that two individuals in the same phase of their life course (of the same age or both at the end of their educational career) can make different choices on family formation, because they have different preferences or attitudes. On the whole, it can be concluded that values define a person in the totality of his behaviour, attitude, goal direction and general orientation of life. Any choice therefore that an individual makes, is navigated and oscillated within the pendulum of life's values.

\subsection{Methodology in MEC}

The method used for data collection in MEC is known as laddering.

\subsection{Laddering Technique}

Laddering refers to an in-depth one-on-one interviewing technique used to develop an understanding of how consumers translate the attributes into meaningful associations with respect to self, following a means-end theory (Gutman, 1982; Reynolds \& Gutman, 1988) . Reynolds and Whitlark (1995) describe it as an interviewing technique that can be used to elicit means-end connections and attribute-consequence- value networks people use when making decisions about life's endeavours. It is qualitative in nature - utilising a semistructured interviewing tool aimed at eliciting responses from respondents' perception on the attribute-consequence-value (A-C-V) elements (Mahmud, 2007). Reynolds and Gutman (1988) assess that laddering involves a tailored interviewing format using primarily a series of directed probes, typified by the "why is that important to you?" question, with the express goal of determining sets of linkages between the key perceptual elements across the range of attributes (A), consequences (C), and values (V). Costa et al., (2004) describe it as faceto-face, individual, in-depth, semi-structured interviews aiming at the elicitation of the attribute-consequence-value associations consumers hold regarding the object(s) under study (Costa et al., 2004).

Laddering technique was first introduced in the 1960s by clinical psychologists as a method of understanding people's core values and beliefs (Hawlev, 2009). Various researchers, Tania et al. (2006), Costa et al. (2004), Grunnet and Grunnet (1995), and Reynolds and Gutman (1988), agree that the laddering technique was developed by Dennis Hinkle in 1965 (PhD dissertation), as a means of modelling people's belief structures; and the term "laddering" was coined by Bannister and Mair (1968) who extensively used the technique in their research. 


\subsection{Prioritised Questioning Structure of Laddering Technique}

In conducting laddering interviews, the right questions may be difficult to come by, and the interviewee may be nervous or uncomfortable with the line of question. To ease this dilemma, Wansink (2003) suggests and sums up the main points that should be prioritised in a laddering interview as: a) ask questions that can reveal personal reasons; b) ask questions that lead the person to think and answer with a sentence, not just responding with a "yes" or "no"; c) keep asking "why"; d) question people's reasons for their answers; e) allow the questioning to flow; f) ask questions that give respondents free reign to answer the questions as they feel appropriate; and g) watch the people's facial expressions as they answer the question and listen to the tone of their voices.

\subsubsection{Conceptual Framework of Laddering Technique}

Laddering technique is generally framed in seven phases for the purpose of data collection, analysis and interpretation. The following phases have been outlined: 1) elicitation of the attributes; 2) selection of the functional attributes; 3) elicitation of the attribute levels; 4) performing laddering interviews; 5) determination and coding of means-end chains; 6) aggregation: construction of hierarchical value map (HVM); and 7) analysis and interpretation of the HVM (Mahmud, 2007; Coolen \& Hoekstra, 2001). These phases are for the purpose of measuring and analysing the various elements and the linkages between them in MEC.

Gengler and Reynolds (1995) sum the steps for the laddering analysis and interpretation as follows: 1) data reduction (data conversion into separated phases); 2) content analysis of the elements selected in the previous steps; 3 ) summation of relations in content codes, resulting in an implication matrix of all paired relationships; and 4) construction of a diagram to meaningfully represent the main implication of the study - the HVM. Several researchers (Mahmud, 2007; Tania et al., 2006; Costa et al., 2004; Coolen \& Hoekstra, 2001; Gengler \& Reynolds, 1995; Reynolds \& Gutman, 1988) are unanimous that content analysis tool is the core of the analytical procedure in a means-end study.

\subsection{Adaptation and Application of MEC in Housing Research}

In this section, we highlight the applicability of MEC in housing research, by reviewing in brief, previous works that utilised MEC model in their housing research. Although MEC was especially designed and developed for use in consumer of merchandised goods and organisation research, it is also becoming popular in other areas due to its versatility (Tania et al., 2006). Mahmud (2007) opines that the adaptation and application of MEC model in housing research is still at its early stage, and as a result, literature on this area is scarce. (see abstract page 1) He considers the works of Coolen and Hoekstra (2001) on housing preference in the Netherlands as probably the first attempt to apply MEC research method to measure the appropriateness of the design of the built environment. Mahmud (2007) in 
following the footsteps of Coolen and Hoekstra (2001), used the MEC model as a research tool to test and measure housing personalisation in Malaysia. These studies, Mahmud (2007) and Coolen and Hoekstra (2001) are probably the pivotal pioneering works that applied MEC model as a tool in housing research. However, prior to these studies, the methodological works of Timmermans et al. (1994) and Molin et al. (1996) on housing choice processes and predicting consumer response to new housing, respectively, probably set up the stage for doing housing research with the application of the MEC model. The studies of Coolen and Hoekstra (2001) utilised one of the methodological models presented in Timmermans et al. (1994). Although Timmermans et al. (1994) did not specifically make reference to MEC in their work, it is clear that the underlying principles for their works were embedded in MEC model as the general framework. Moreover, the basic constructs or variables of MEC make up the basic components of the housing choice and preference measurement models - the revealed and stated models - as presented by Timmermans et al. (1994).

Both Mahmud (2007) and Coolen and Hoekstra (2001) found the MEC model as a veritable tool for housing research. Mahmud (2007) used MEC model to explore people's behaviour in changing their living environments (housing-personalisation). He found out that housing users' personal design expectations have been a direct influence on the physical modification of their houses. On the other hand, Coolen and Hoekstra's (2001) pilot study on housing preference in the Netherlands which centred on people's behaviour in choosing living environment, found that values are one of the determinants in housing choice and selection. Based on their findings, these researchers make the following conclusions: firstly, that the application of MEC model for identifying users housing expectations will be useful in housing design process, and can be tested in housing design towards a more suitable living environment, hence good housing (Mahmud, 2007), and, secondly, that housing choice and preference behaviour is also value-oriented and goal-directed behaviour like any other product choice behaviour (Coolen and Hoekstra, 2001).

\subsection{The Revealed and Stated Choice Models}

The methodological works in Timmermans et al. (1994) broadly presented two measurement housing choice and preference modelling approaches as: the revealed models of housing choice and the stated models of housing preference and housing choice. Both models have the following common assumptions: firstly, they assume that houses or residential environments can be described and qualified in terms of a set of attribute levels; secondly, they assume that individuals or households derive some part-worth utility from each of the attribute levels; and thirdly, they assume that individuals combine their partworth utility according to some rule to arrive at an overall preference or choice (Orzechowski, 2004; Timmermans et al., 1994). However, according to Coolen and Hoekstra (2001), these models contrast with the laddering measurement approach. 


\subsection{Conceptual Structure of the Models}

The revealed models are based on observational data of households' actual housing choices (Orzechowski, 2004; Coolen \& Hoekstra, 2001); while the stated models are based on intended housing choices or hypothetical housing choices (Coolen \& Hoekstra, 2001), and are based on the premise that observed housing choices will always reflect the joint influence of preferences, market conditions, and availability (Orzechowski, 2004). These models have been expanded to several modelling approaches:

\subsubsection{The Revealed Models}

Often, the aim of studying housing choices and preferences using these models is to identify the nature and strength of the relationship of the probability of choosing a particular housing type and a set of spatial and socio-demographic variables. According to research (Louviere \& Timmermans, 1990; Timmermans \& van Noortwijk, 1995; Dieleman, 1996; Wang \& Li, 2002), these studies are primarily descriptive, which have increased the understanding of housing markets substantially.

\subsubsection{The Stated Models}

Stated preference approaches can be further classified and distinguished into algebraic and non-algebraic methods.

\subsubsection{Algebraic Methods}

They use a mathematical expression to relate the utility of attribute levels to measure of overall preference. There are two algebraic methods: the compositional approaches and the conjoint preference models. Compositional approaches recommend that housing preferences are measured by letting people select the preferred level of each of a number of housing attributes and by having them indicate the relative importance of each attribute. Conjoint preference models are based on the measurement of people's evaluations of housing profiles. Individuals are requested to express their overall preference for each profile by ranking or rating the profiles (Orzechowski, 2004; Coolen \& Hoekstra, 2001; Timmermans, 1984).

\subsubsection{Non-algebraic Methods}

Timmermans et al., (1994) state that non-algebraic models are alternative to algebraic models to handle more complicated if-then structures which algebraic models by definition cannot represent. Orzechowski (2004) opines that non-algebraic models have the main advantage of flexibility over the algebraic approaches. Like the algebraic models, nonalgebraic models have two approaches: the decision nets, representing a structure interviewing technique (Orzechowski, 2004; Coolen \& Hoekstra, 2001; Timmermans et al., 1994), and the measurement approaches - representing the semi-structured interviewing technique (laddering) (Coolen \& Hoekstra, 2001). The aim of decision nets is to disentangle the decision-making process (Orzechowski, 2004), or to disentangle people's intended 
housing choice behavior (Coolen \& Hoekstra, 2001). Here people are requested to identify the housing attributes that influence their preference, then for each of these attributes, they have to determine at which level of the attribute an alternative would no longer be acceptable (Orzechowski, 2004; Coolen \& Hoekstra, 2001). In the measurement approaches, people are to identify which housing attributes are important for them; indicate the level of attribute they prefer; determine the underlying reasons of the preference for a certain level; and to process housing attributes from a motivational perspective (Coolen \& Hoekstra, 2001). The conceptual structure of these measurement models can be illustrated as in Figure 3.

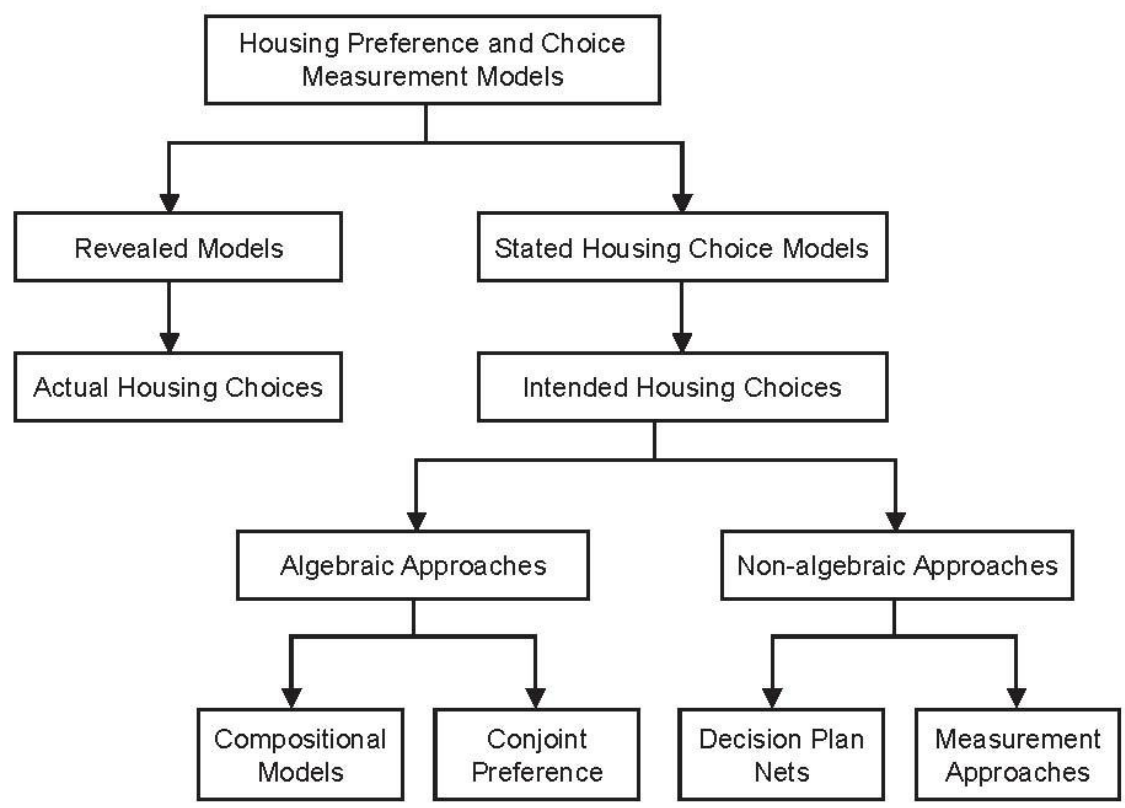

Figure 3: Conceptual Structure of Housing Choice \& Preference Models (Source: Orzechowski, 2004; Coolen \& Hoekstra, 2001; Timmermans et al., 1994).

\section{0 Discussion \& Conclusion}

In this paper, we have explored from various literatures the Means-End Chain model as a tool, and its applicability to housing research, although its initial intentions and purposes were geared towards merchandised consumer goods and services research. We also explored the relationship between an individual's choice and preference behaviour as it relates to housing attributes in the MEC model, which conceptual framework was also presented. Although the applications of the MEC model in housing research and its 
attendant linkages is still at its relatively infant stage, it is found from the few studies conducted, that using the MEC model as a tool has been very positive in performance and proved that MEC can be relied on in conducting housing research. Since the application of MEC is still at an early stage in housing research, it then presupposes that a lot and vigorous housing research needs to be carried out with MEC model.

Laddering, which is undoubtedly a useful technique for identifying the relevant attributes and life values in a particular product domain, and for studying the complexity of consumers' cognitive structures with respect to that domain, can fruitfully be combined with a questionnaire technique in eliciting responses from housing users to determine their choice behaviours. It could also be used with any of the other models presented in this paper.

The few researches conducted have been done mostly in the area of spatial configuration of the housing product - the house. The house which is made of diverse and heterogeneous attributes requires that other aspects of the housing attributes need to be researched into, and the attendant motivations for the housing user in choosing a set of housing attributes over and above alternative sets of housing attributes. Besides the spatial configuration attributes (e.g. the size or number of rooms) of the house, there are other attributes of the house like concealed attributes (e.g. reinforcements, substructure, beams, columns, etc.), exposed attributes (e.g. fittings, finishes, etc.), elemental components (e.g. windows, doors, etc), roof style (e.g. gabled, hipped, flat, etc), and aesthetics attributes (e.g. the treatment of the external features of the building), that require further research. Spatial dimensional attributes of housing (e.g. the sizes of the rooms, both horizontal and vertical) is also another area that requires further research. For each of these attributes, there are motivational reasons for the preference and choice behaviour of the user in deciding for each set of preferred attributes alternatives.

The MEC research model is a worthy tool that will unveil the hidden motivations for these choices. In dealing with user choice and preference of housing attributes, there is a need for research for the development of a technology tool for the identification of user needs, choice and preference, and the kind of decision support that are required to identify these needs. In summary, MEC is found to be a very vital and useful research tool; therefore we strongly recommend the use of MEC model as a tool for housing research.

\section{Acknowledgement}

This study was made possible by the continuous support from Universiti Teknologi Malaysia.

\section{References}

Bannister, D., \& Mair, J. M. M. (1968). The Evaluation of Personal Construct. London: Academic Press. 
Blaauboer, M., \& Clara H. Mulder (2007). Residential Choice and Attitudes towards Family and Work. Amsterdam: University of Amsterda.

Block, A. (1946). Estimating Housing Needs. London: The Architectural Press.

Boer de, M. M., B. McCarthy. (2004). Means-End Chain Theory Applied to Irish Convenience Food Consumers. Cork: National University of Ireland.

Botschen, G., Thelen, E. M., \& Pieters, R. (1999). Using Means-End Structures for Benefit

Segmentation and Application to Services. European Journal of Marketing, 33(1-2), 38-58.

Coolen, H., and Hoekstra, J., (2001). Values as Determinants of Preferences for Housing Attributes. Journal of Housing and Built Environment 16, 285-306.

Coolen, H., Boelhouwer, P., and Kees, V. D. (2002). Values and goals as determinants of intended tenure choice. Journal of Housing and Built Environment, 17, 215-236.

Costa, A. I. A., M. Dekker and W. M. F., Jongen. (2004). An overview of means-endtheory: potential application in consumer-oriented food product design. Trends in Food Science \& Technology (15), 403-415.

Dibley, A., \& Baker, S. (2001). Uncovering the Links between Brand Choice and Personal

Values among Young British and Spanish Girls. Journal of Consumer Behaviour, 1(1), 77-93.

Dieleman, F. M. (1996). Modeling Housing Choice. Netherlands Journal of Housing and the Built Environment (11), 201-207.

Gengler, C. E., \& Reynolds, T. (1995). Consumer Understanding and Advertising Strategy: Analysis and Strategic Translation of Laddering Data. Journal of Advertising Research, 35(4), 19-32.

Gengler, C. E., Mulvey, M. S., \& Oglethorpe, J. E. (1999). A Means-End Analysis of Mother's Infant Feeding Choices. Journal of Public Policy and Marketing, 18(2), 172-188.

Grunert, K. G., \& Grunert S. C. (1995). Measuring subjective meaning structures by the laddering method: theoretical considerations and methodological problems.

International Journal of Research in Marketing (12), 209-225.

Gutman, J. (1982). A Means-End Chain Model based on Consumer Categorization

Processes. Journal of Marketing, 46, 60-72.

Hawlev, M. (2009). Laddering: A Research Interview Technique for Uncovering Core Values: Research That Works.

Hinkle, D. (1965). The Change of Personal Constructs from the viewpoint of Theory of

Construct Application: Unpublished Doctoral Dissertation. Columbus, Ohio: Ohio State University. 
Zinas, B.Z., \& Mohd Jusan, M. / Asian Journal of Environmen-Behaviour Studies, ajE-Bs, 2(2) Jan / Mar 2017 (p.23-37)

Kaciak, E., \& C. W., Cullen. (2006). Analysis of means-end chain data in marketing research. Journal of Targeting, Measurement and Analysis for Marketing (15), 12- 